\title{
Organizational Goals Versus the Dominant Coalition: A Critical View of the Value of Organizational Citizenship Behavior.
}

\author{
Wm. Matthew Bowler \\ Oklahoma State University
}

\begin{abstract}
Organizational citizenship behavior is believed to promote organizational goals. However, it is unlikely that all organizational citizenship behavior supports organizational goals. Because citizenship behavior is not formally mandated by the organization, such behavior is influenced by informal forces within and around the organization. This article presents a critical view of organizational citizenship behavior by examining the influence of informal power sources, such as the dominant coalition, on citizenship behavior. Future research implications and practitioner suggestions are discussed.
\end{abstract}

\section{Introduction}

For the past twenty years management scholars have examined organizational citizenship behavior primarily under the assumption that such behavior promotes organizational goals and effectiveness. Few researchers (Bolino, 1999; Bolino \& Turnley, 2003) have questioned this assumption while focusing upon the antecedents and consequences of OCB. It has been suggested that not all organizational citizenship behavior promotes organizational goals, rather, OCB may further goals other than the formal goals of the organization. At the individual level it has been suggested that OCB may be motivated by other drivers such as impression management motives (Bolino, 1999, Rioux \& Penner, 2001), rather than enhancing organizational effectiveness. This individual level ulterior motive is a departure from the original assumption that parallels the organizational level phenomenon of goal complexity.

At the group level of analysis a great deal of attention has been given to examining the idea that the stated goals of the organization are not the exclusive goals of the organization (Perrow, 1993). Stated organizational goals are supplemented and undermined by the unstated goals of those who maintain informal control of the organization. If dominant coalitions are able to influence the formal goals of the organization that drive in-role behavior, it seems likely that dominant coalitions influence and benefit from extra-role behaviors such as OCB.

Bolino and Turnley (2003) explored antecedents to OCB along with the potential positive and negative outcomes of OCB. One antecedent discussed was the informal organization as a precursor to OCB. They accurately described the potential positive role of a strong organizational culture on OCB. However, the potential negative outcomes that could be tied to the informal influence of dominant coalitions, a potential strong informal structure, on OCB were not addressed. 
This article, therefore, builds on the work of Bolino and Turnley (2003) by exploring the role of dominant coalitions in influencing OCB. To achieve this we first review relevant OCB literature to introduce and discuss the role of formal and informal influences on OCB. We then review literature on dominant coalitions and their role in the influence and supplanting of organizational goals. Based on these two discussions propositions are developed to explain how the goals of the dominant coalition, rather than the stated goals of the organization, may actually be the primary driver and beneficiary of OCB. Figure 1 depicts a potential model of the influence of dominant coalitions on OCB. Finally, recommendations for future research and practitioners involving dominant coalitions and OCB are discussed.

Figure 1: Model of Dominant Coalition on OCB

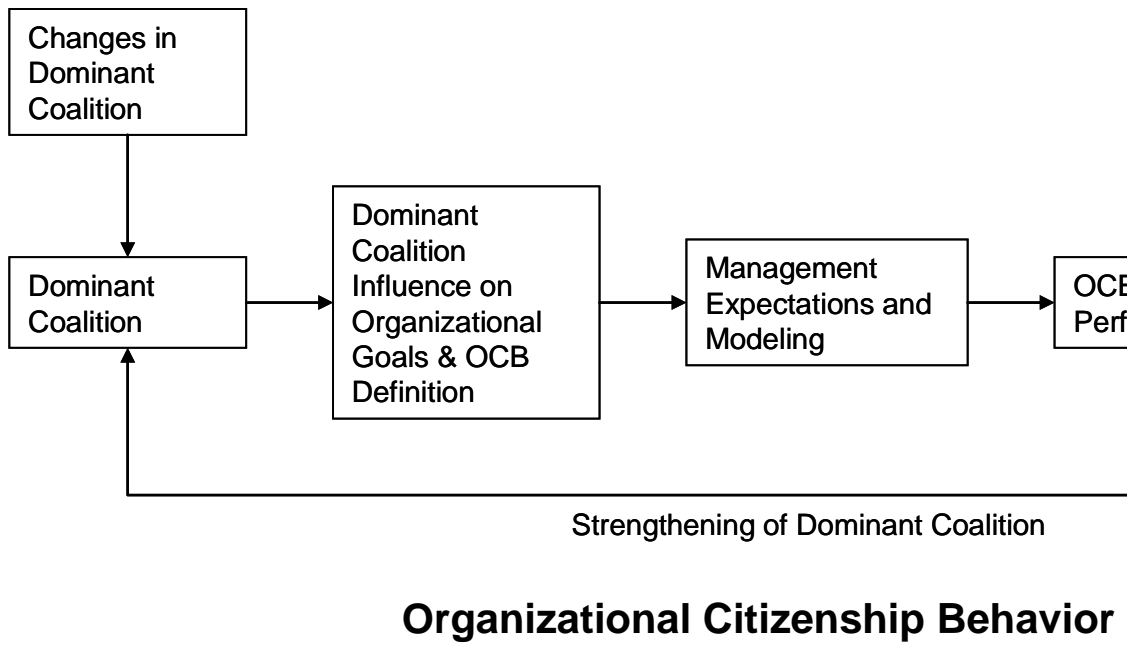

Organizational citizenship behavior is defined as "individual behavior that is discretionary, not directly or explicitly recognized by the formal reward system, and that in the aggregate promotes the effective functioning of the organization" (Organ, 1988: 4). Highly valued by organizations, OCB enhances organizational functioning (Organ, 1988, Podsakoff, Mackenzie, Paine, Bacharach, 2000). Prior to Organ's introduction of the idea of citizenship behavior, Katz (1964) recognized the value of extra-role behavior and its criticality to the functioning of any social system. Katz stated that any social system depending only on "blueprints for prescribed behavior" (p132) is a fragile social system, thus suggesting that some level of extra-role behavior is necessary to ensure the survival and success of social systems. Therefore, not only business organizations, but all social systems, reap the harvest of individual extra effort.

The real world value of citizenship behavior has also been supported by empirical research. In a recent finding, Koys (2001) found citizenship behavior leads to subsequent enhanced organizational performance. Meta-analytical research by Podsakoff (2000) and his colleagues linked OCB to individual, group, and firm level performance. A number of reasons why OCB are performed and how OCB benefit the organization have been suggested and studied. Social 
exchange theory is the most common explanation of why employees perform OCB.

Social exchange theory (Blau, 1964) suggests that citizenship behavior can be expected when an employee experiences positive affect toward the organization and is motivated to reciprocate to the organization the experiences that cause the positive affect. Although there is potential for negative effects of OCB (Bolino \& Turnley, 2003), in general OCB facilitates the effective functioning of organizations in a number of ways. Interpersonal OCB helps employees work together (Koys, 2001). Organizational citizenship behavior also helps coordinate information and activities within groups (Podsakoff \& Mackenzie, 1997). Citizenship behavior is linked to customer satisfaction (Morrison, 1997) and financial performance (Walz, 1996). It is clear that OCB affects the performance of the organization, however at this point it is important to explain that OCB are not all alike in nature or consequence.

OCB has four separate, but related behavior elements that differ in their target and direct objective. It is believed that the indirect objective of all OCB is the benefit of organizational goals (Organ, 1988). In a theoretical typology developed by Graham (1989; Moorman \& Blakely, 1995; Moorman, Blakely, Niehoff, 1998) OCB categorizes into four types: personal industry, loyal boosterism, individual initiative, and personal helping. Personal industry represents the extent to which an individual performs tasks beyond the call of duty. Employees who spontaneously work overtime, put in extra hours on a project, or volunteer to take on new projects are engaging in personal industry. Loyal boosterism represents the promotion of firm image to outsiders. An employee that spontaneously compliments his employer to a member of another firm, a friend, or any stakeholder displays loyal boosterism behavior. Personal industry and loyal boosterism directly benefit the organization's goals.

Interpersonal helping and individual initiative both benefit the organization indirectly through the enhanced performance of OCB recipients. Individual initiative represents communicating with others in the organization to improve individual and group performance. (Graham, 1989; Moorman \& Blakely, 1995; Moorman, Blakely, Niehoff, 1998). An employee, recognizing that a co-worker might benefit from possession of a piece of information, such as a sales contact, technical information, or market tip, and passing on such information without the other asking for it, exemplifies individual initiative OCB (Podsakoff, \& Mackenzie, 1994). Interpersonal helping entails a co-worker assisting another in the organization resulting, either directly or indirectly, in enhanced individual job performance ultimately contributing to organizational functioning. Settoon and Mossholder (2002) used the term interpersonal citizenship behavior to describe interpersonal helping. Their study examined interpersonal helping that is task related and non-task related in the context of social network structures. These interpersonal OCB prove vital when discussing the influence of dominant coalitions on OCB. 
To summarize, OCB consist of non-obligatory, informally influenced behaviors. Prior research demonstrates that OCB results from such informal influences as leader modeling, group cohesiveness, and leader member relations (Podsakoff et al., 2000). Given that these positive influences are affecting OCB performance, then it is also possible that dominant coalitions also influence OCB.

\section{Dominant Coalitions}

A dominant coalition consists of the network of individuals within and around an organization that most influence the mission and goals of the organization (Cyert \& March, 1963). In theory, the goals of an organization flow from the chief executive officer, board of directors, or top management team. However, the dominant coalition maintains an influence on goals through informal, rather than formal, channels. This allows individuals other than formal leadership to manipulate the goals of the organization. Top management members are typically, but not exclusively or necessarily, members of the dominant coalition. Control or possession of important organizational resources allows the dominant coalition to leverage those resources thus manipulating the organization to achieve individual or group goals rather than organizational goals (Pfeffer \& Salancik, 1978). Some of the resources that might be included are access to physical resources, or capital, possession of tacit knowledge, or position in a network such as a structural hole that provides the individual with exclusive access to individuals and vital information (Burt, 1992).

Coalition members need not be within the organization. Any supplier, customer, or other stakeholder with significant control over the organization's distribution channel(s) or decisions could exercise influence within the dominant coalition. For example, Provan and Skinner demonstrated the influence of suppliers upon customers when the supplier is the exclusive outlet for important resources (1989). These powerful organizations could influence the goals of the target organization through informal influence. However, power is a necessary but not sufficient condition for subverting stated goals.

Intention is another necessary variable. An exclusive supplier or powerful actor could possess power without a desire to alter organizational goals. When intentions of dominant coalition members match those set by the formal leadership, they will support and pursue the stated goals. However, when coalitional goals contradict those of formal leadership, the stated goals of the organizational often do not match the actual behavior of the organization. Goal complexity (Gouldner, 1960) suggests that organizations do not pursue their stated goals exclusive of informal goals. Some organizations pursue only altered versions of their stated goals because of informal forces, such as dominant coalitions, within the organization. Other organizations may pursue their actual stated goals, but even those goals are not the exclusive goals pursued by the organization. In addition to pursuit of the stated goals, according to Gouldner, the organization will also have unstated, informal goals that affect organizational functions. 
According to goal theory (Locke \& Latham, 1990), formal and informal goals regulate and determine both in-role and extra-role behaviors within organizations. Formal goals are primarily achieved through the use of such things as job descriptions and management guidance of behavior, but are also aided by extrarole behavior. Informal goals are primarily accomplished through extra-role behavior but, the accomplishment of those goals also depends upon the institutionalization of informal power sources such as dominant coalitions (Cyert \& March, 1963). Through this legitimization of power into the formal channels of the organization dominant coalitions are able to influence behavioral standards as well as management expectations of both in-role and extra-role behavior. Figure 1 depicts a model of the influence of dominant coalition forces on OCB.

Because OCB is not specifically mandated or rewarded by formal job descriptions, the informal influence of managers is vital. Management has a great deal of indirect influence upon extra-role behavior such as OCB. Several modes have been suggested for management influence upon OCB. Included in those influences are performance expectations, fostering acceptance of group goals, and providing an appropriate model (Podsakoff et al., 2000). If the expectations of the manager are that the employee will perform in a manner consistent with coalitional rather than organizational goals, the employee would be more likely to perform OCB that support coalition goals. Managers who are part of the dominant coalition, or influenced by the goals and objectives of the coalition are likely to provide a behavioral model that is consistent with coalitional goals. Such a behavioral model would impact employee definitions of OCB causing it to support the goals of the dominant coalition.

Therefore, OCB supports both the goals of the dominant coalition along with, or in place of the formal goals and mission of the organization.

\section{P1: Organizational citizenship behavior promotes the goals of the dominant coalition.}

Coalitions are only somewhat stable in their makeup and their influence. Many forces influence stability and change in and around organizations and also affect the makeup and intent of dominant coalition. Forces for stability include the survival goals of the dominant coalition, organizational momentum, and the embeddedness of the organization (Greenwood \& Hinings, 1996). Members of the dominant coalition desire to remain in the dominant coalition and maintain influence over the organization in order to achieve their ulterior coalition motives. The organization's current direction produces a certain level of momentum both internally through the stability of departments and capital allocations, as well as externally through long term contracts and relationships. However, any environmental, cultural, or technological shift could affect the structure of the organization and ultimately the structure of the dominant coalition. The result of such change would be the alteration of coalitional goals and behaviors. 
A technological change within an organization may provide the impetus for power changes within the organization. Burkhardt and Brass (1990) studied the introduction of a new computer technology into a governmental agency. They found that early adopters of the technology gained a significant amount of informal power in the organization, which could be used to join or enhance one's membership in the dominant coalition. Thus, such changes in technology could result in altered membership in the dominant coalition.

The dominant coalition may also include individuals whose principal association is outside of the firm of interest (Pearce II, 1995). Changes must then be examined by including the organizations with which the firm has relationships. Institutional theorists suggest that these outside forces exert a great deal of influence upon the functioning of the organization (Selznick, 1949). Once an organization is developed, it becomes concerned with survival. Survival is dependent upon the maintenance of certain key relationships with external individuals and firms. Those firms are therefore able to leverage their relationship power to informally influence the goals of the focal organization. The powerful external entity would then be considered part of the dominant coalition. However, if some change occurred in the organizational context that changed the nature of the firm's external dependence, there would be a change in the membership of the dominant coalition. For example, the introduction of a new supplier of a vital resource would cause a shake-up in the current status quo of the relationships of the organization. The prior supplier would have less influence than before, and the new supplier would move into a position of power and gain access to, or membership in the dominant coalition. This example would apply to many situations regarding external members of the dominant coalition. Vital financing resources, customers, and regulatory bodies are among the many external influences that could be part of the dominant coalition at any one time, and would change as the environment changes. These changes would result in altered makeup of the coalition and its goals. Changes in the goals would cause changes in the behaviors and expectations of managers, ultimately altering the extra-role behaviors of employees.

The changing definition of OCB would not necessarily be visible. The change might remain be small enough to remain within the context of the four types described by Moorman, et al. (1998). Settoon and Mossholder (2002) examined interpersonal helping that was task focused and that which was person-focused related as distinct constructs. While empirically the two were closely related $(r=$ .79), intuitively one can imagine how they might differ. Either one could be altered by changes in the dominant coalition. First, alignment with formal organizational goals would reward and model task-focused interpersonal helping that supports those formal goals. However, a change in the dominant coalition to one that has goals divergent from the formal goals might result in changes in the task-focused interpersonal helping to behaviors that support dominant coalition in addition to or in lieu of the formal goals. For example, operating under dominant coalition influence an individual might help more on projects that are headed by dominant coalition members while withholding help from individuals that are 
working on projects not supported by the dominant coalition. Further, because the dominant coalition can extend beyond the organization, interpersonal helping could be designed to enhance the stakeholders that are members of the coalition rather than helping stakeholders that are not part of the coalition.

Within the person-focused interpersonal helping behaviors, the influence of a dominant coalition could change the people that one is willing to help, or the type of help or advice that one gives. An individual operating under the influence of the dominant coalition would likely give advice that might support coalition members, or that could facilitate the cooptation of non-coalition members into supporting the coalition rather than supporting the formal organization through these behaviors.

Under the influence of the dominant coalition, employees would be likely to positively portray coalition members and specific goals to outsiders rather than promoting the organization as a whole. Dominant coalition members and those influenced by the coalition would be less likely to attend organizational and social events sponsored by coalition outsiders, but attend events sponsored by members of the dominant coalition. This could lead to long term rupturing of relationships and social capital which would erode the actual objectives of organizational functions.

Individual initiative OCB that is defined by the dominant coalition might lead to changes in how an employee communicates and shares information in the workplace. If the individual sees the power and influence of the dominant coalition as superior to the formal leaders, the individual would be likely to disseminate information or rumors in ways that support the coalition rather than that which supports the goals of the organization or jeopardizes the dominance coalition. This could circumvent formal goal attainment at the individual, group, and organizational level in exchange for supporting the goals of the dominant coalition.

Finally, going beyond the formal job requirements on formal tasks, personal industry could be influenced by the dominant coalition as well. Putting in overtime, or working on the weekend when it is not required might increase or decrease under the influence of the dominant coalition. The goals of the dominant coalition could influence which projects an individual spends overtime working on or which projects are subject to procrastination. For example, an individual influenced by the goals of the dominant coalition working on contracts for two sales reps would be more likely to provide superior service to the contract that is serviced by the fellow dominant coalition member. This could result in the failure of the other contract, substandard performance by the sales representative that is not a member of the dominant coalition, and improved performance by the sales representative that is a member of the dominant coalition. This in turn would further the power of the dominant coalition and enhance its impact on the definition of OCB. 
Therefore, it is expected that the membership of dominant coalition and its goals will influence the definition and target of OCB. Further, as the dominant coalition changes so too will the definition and target of OCB.

P2: As membership of the dominant coalition changes, so to will its goals, resulting in changes in the definition and target of organizational citizenship behavior.

The existence of a dominant coalition suggests the existence of other coalitions, as well as independent actors within the organization. While the primary goal of the dominant coalition is the continuation of its control (Cyert \& March, 1963), those outside the dominant coalition would have different goals, whether they come from formal roles, individual objectives, or other informal influence. The existence of multiple goals results in multiple definitions of citizenship. Those working toward the maintenance and fostering of the dominant coalition would perform OCB in support of the dominant coalition, what could be labeled dominant coalition citizenship behavior (DCCB). Non-members of the dominant coalition likely perform OCB that are more in line with organizational goals rather than the goals of the dominant coalition. Assuming though that someone is either in or out of the dominant coalition's sphere of influence is not sufficient. The boundary defining of the dominant coalition is a nebulous gray area. Therefore, it is more accurate to suggest that employees vary in their proximity to the influence of the dominant coalition. That distance might be in measured in relational, physical, or organizational structure units from the center of the dominant coalition.

Bolino and Turnley (2003) discussed two forces affecting the performance of OCB that also relate to dominant coalitions. First, they discuss the effects of leadership on OCB performance. This suggests that managers and supervisors influence the performance and definition of OCB through a number of channels including support and modeling. Second, they suggest the power of informal social pressures on individual behavior that is discretionary such as OCB. These two forces, combined with the existence of a dominant coalition would impact the likelihood that an employee would perform DCCB.

Employees or managers that are dominant coalition members would be most the likely to perform DCCB because of the informal social pressures of the dominant coalition. Employees that are not part of the dominant coalitions, but whose managers are dominant coalition members would be also likely to perform DCCB rather than OCB. Managers that are part of the dominant coalition are likely to model and expect behaviors that would support the dominant coalition rather than behaviors that support the organization's goals. The influence of OCB role modeling by supervisors has been found by Podsakoff, Mackenzie, and Bommer (1996). However, employees more distant from the dominant coalition and its sphere of influence would be less susceptible to their definition and role modeling of citizenship in the form of DCCB. Similar to the debate as to whether OCB is truly extra-role, or is in-role in nature, this brings to the surface a potential debate 
regarding which behaviors are organizational citizenship and which behaviors represent citizenship of the dominant coalition. The goal here is not to explicate the difference between behaviors, but to suggest how OCB might be influenced by the dominant coalitions. In fact, as suggested by Bowler and Brass (in press) the behaviors are likely often the same, but targeted differently, or performed at different intensities or frequencies in order support goals of either the organization or the dominant coalitions. Therefore, proximity to the dominant coalition will affect an individual's definition of OCB.

P3: Proximity to the dominant coalition will alter one's definition of organizational citizenship behavior.

Two OCB types, personal industry and loyal boosterism, are directed primarily at the organization without benefiting others within the organization. The other two, interpersonal helping and individual initiative, involve the direct benefit of others and indirect benefit to the organization (Graham, 1989: see Moorman \& Blakely, 1995). While the organization ultimately benefits, the performance of the latter two OCB types lead indirectly to enhanced organizational performance by directly helping others. The existence of coalitional forces within the organization would lead to two possible explanations for who would directly benefit from the performance of the two interpersonal forms of OCB. The first explanation involves OCB directed at members of the dominant coalition and is discussed next. The second involves OCB directed at non-members of the dominant coalition and is part of proposition four below.

One method available to the dominant coalition for ensuring survival is in helping other members maintain powerful positions. This can be accomplished in part through the performance of dominant coalition OCB that support the positions of fellow coalition members. By providing coalition members with valuable information and helping them with projects, members can maintain the strength of the coalition and the non-substitutability of each individual member. Several researchers have suggested and found evidence for increased OCB within groups because of the social and task structures that facilitate the performance of OCB through relationships, trust, and regular exposure to one another in the workplace (Anderson \& Williams, 1996; Lamertz, 1999, Settoon \& Mossholder, 2003).

From a social network perspective, Bowler (2001) suggested that members of high density groups and cliques would be more likely to perform OCB toward fellow group members. Membership in such groups provides the strength of relationship necessary for the establishment of social exchange relationships. Group members' relationships with nonmembers are based on weaker bonds and economic exchange principles insufficient for OCB performance.

Karambayya (1990) found that OCB performance differed by group and that the intended recipient of the OCB was more often a fellow group member. Similarly, coalition members are likely to have more mature relationships with one another than coalition non-members. This would result in OCB directed at fellow coalition 
members rather than non-members. Therefore, in order to maintain the structure and solidarity of the dominant coalition, coalitional members will perform OCB toward other coalition members more often than toward non-members.

P4a: Coalition composition will be maintained through performance of organizational citizenship behaviors directed toward other dominant coalition members.

Alternatively the coalition could view its survival from Barnard's (1938) viewpoint, seeing their power as granted to them by those they influence. This viewpoint would require members of the dominant coalition to maintain their position as the informal power center of the organization with the coalition non-members. Two methods for cultivating the position of the dominant coalition with outsiders would include creating obligations with outsiders and/or managing impressions held by outsiders of dominant coalition members.

Drawing on the norm of reciprocity (Gouldner, 1960), dominant coalition members performing OCB for those outside the dominant coalition further cement their position as the power center of the organization. The norm of reciprocity describes the universal reactions of individuals receiving help and suggests that individuals need to feel balance in exchange relationships. In fact, individuals prefer a feeling of positive imbalance to that of indebtedness (Blau, 1964). In order to avoid feeling obliged to another, an individual will provide a reciprocal favor to maintain equilibrium or a positive imbalance.

Members of the dominant coalition could ensure the availability of future help from non-members by maintaining such a positive imbalance and thus using the other's reciprocity need to their advantage. When a member of the dominant coalition performs an OCB directed at a non-member the recipient experiences an innate need to repay the individual for their assistance. The norm of reciprocity does not specify the manner or timing in which the exchange should occur, only that the recipient feels a psychological contract to repay the other in the future. Because members of the dominant coalition sow a need to reciprocate in the recipients of OCB, they are able to recall the favor at a future specified date and the original recipient will feel a need to reciprocate. Additionally, dominant coalition members are powerful within the organization and pose a coercive threat to the OCB recipient if the favor is not repaid. When thinking of creating obligations one is reminded of Vito Corleone in The Godfather saying "Someday, and that day may never come, I'll call upon you to do a service for me." The recipient of the favor from Vito Corleone knew that the favor must be repaid sometime in the future, or suffer the consequences. Similarly, members of the dominant coalition can supply favors that can be recalled in the future for enhancement of the dominant coalition, its power, or its objectives. Such a coercive use of OCB is not the only means for bolstering the dominant coalition. Rather, a more subtle approach would be to use OCB to maintain a positive image of dominant coalition members in the eyes of dominant coalition nonmembers. 
As Bolino (1999) suggested, a significant portion of OCB performance is directed at creating a positive image in the eyes of other employees. Based on impression management theory the survival and success of the dominant coalition depends in part on those relationships that are maintained and leveraged external to the coalition. Managers involved with the dominant coalition would give information and help to non-coalition employees in order to maintain a positive reputation. That reputation as an organizational citizen provides dominant coalition members with access to information and resources that could facilitate the dominant coalition and its objectives. Unless the nonmembers are able to detect the ulterior motive of the OCB performer, the impression management driven OCB would maintain nonmember support, ensure coalition survival, and further coalitional goals. Therefore, the performance of interpersonal OCB (such as interpersonal helping and individual initiative) by members of the dominant coalition will be directed at non-members in order to maintain and bolster the dominant coalitions.

P4b: Members of the dominant coalition will maintain their coalition by performing organizational citizenship behaviors through direction of that behavior toward non-member supporters of the dominant coalition.

\section{Discussion}

Management literature is replete with studies of the antecedents and consequences of OCB. It is generally assumed that OCB is a constructive, if not vital, part of the behavior of employees. Additionally, scholars have shown that OCB enhances the performances of groups, and organizations. However, it seems questionable at best to believe that all of what is considered OCB is constructive behavior for the organization.

On an individual level it has been suggested that scholars should take a more critical view of OCB motives (Rioux \& Penner, 2001). Here, that suggestion is being taken a step further to posit that at the organization level, OCB may not be encouraged in ways beneficial to the organization. It may be that some portion of OCB is not organizationally focused or citizenship behavior at all. More than likely some portion of OCB occurrence is oriented at individual motives of impression management, Machiavellianism, or deceit (Bolino, 1999). It also seems plausible that OCB encouraged by organizational leaders and modeled by management is not intended for the benefit of the organization (Bowler \& Duffy, 2002). A more reasonable proposition is that OCB is encouraged in order to fulfill some organizational or group level ulterior motive developed by the dominant coalition. Included in the possible motives are coalition survival, and coalitional goals. These are aspects of OCB that need to be recognized and brought into the mainstream of OCB research.

One foreseeable challenge is the operationalization of OCB as defined by the dominant coalition, and how to isolate that from not only OCB but also in-role behaviors. One possible way to approach such a study would be to query 
members of the organization for their definitions of OCB. This could be done in a manner similar to that which has been used to isolate OCB from in-role behavior definitions (for a complete review see Vey and Campbell, 2004). Then, using social network analysis researchers could identify those people that are members of the dominant coalition as well as calculating the distance of all other employees relationally, physically, or structurally from dominant coalition members. Finally, the correlation between one's connection to the dominant coalition and one's definition of citizenship could be analyzed. To examine changes the definition of OCB in relation to changes in the membership of the dominant coalition a longitudinal study would be necessary. There are certainly other ways in which these propositions could be studied. However, it is important to at least suggest a method of operationalizing and studying propositions proffered based on theory.

If the relationships presented here are substantiated by research there would be several consequences for both research and practice. By including these unfavorable motives researchers will likely discover a new set of motives and methods for performance of OCB such as the impression management motives suggested by Bolino (1999) and studied by Rioux and Penner (2001). It could be suggested that this unfavorable form of OCB is merely a passive form organizational deviance. However, unlike deviant behaviors, OCB provides some benefit within the organization on the surface. It is important to dig below that surface and reveal the real, unstated goals of groups and individuals within and around organizations that drive OCB.

Extricating dominant coalitional citizenship behavior from OCB would provide at least three benefits to researchers. First, DCCB could be researched as a separate construct. This construct would provide much needed integration of organization theory with organizational behavior research. This crossover could provide a means for explaining some of the organization level drivers of individual behavior. Second, separating the negative consequences of DCCB on organizational performance from the documented positive effects of OCB could provide additional support for the value of organizationally focused citizenship behavior. Third, the literature on power and politics in organizations could be enhanced. Understanding the effects of dominant coalitions on OCB will help researchers explain the relationship between political motivations and the resulting nature and direction of extra-role behaviors.

For management practitioners this critical view of OCB should come as an alert to be aware of the unspoken influences of the dominant coalition on discretionary behavior. To adapt and react to such forces one must first recognize that a dominant coalition exists within and around the organization. While it may appear harmless or even beneficial to the organization in fulfilling its mission, the dominant coalition has its own goals that may, or may not, coincide with those of the organization. Managers that recognize these groups maintain an edge in preventing unproductive and subversive behavior on the part of coalitional members and those that the coalition influences. They will also be able to 
recognize the positive role of legitimate OCB and promote it within the organization.

OCB is a vital part of the performance of individuals, groups, and organizations. But, not all OCB is what it appears. Scholars and practitioners must recognize and address dominant coalition forces that affect many parts of the organization including OCB. Recognizing the influence of the dominant coalition will allow researchers to investigate new motives that drive particular OCB types and decipher the outcomes of both constructive, organizationally focused OCB and dominant coalition OCB.

\section{References}

Anderson, S. E., Williams, L. J. (1996). Interpersonal, job, and individual factors related to helping processes at work. Journal of Applied Psychology, 81, 282296.

Barnard, C. (1938). The Functions of the Executive. Cambridge, MA, Harvard University Press.

Blau, P. (1964). Exchange and power in social life. New York, Wiley.

Bolino, M. C. (1999). Citizenship and impression management: Good soldiers or good actors? Academy of Management Review 24(1): 82-98.

Bolino, M. C., Turnley, W. H. (2003) Going the extra mile: Cultivating and managing employee citizenship behavior. Academy of Management Executive 17(3): 60-71.

Bowler, W. M. (2001). Social network analysis of organizational citizenship behavior: Structural determinants of interpersonal helping and individual initiative in organizations. Annual Proceedings of the Southern Management Association Annual Meetings, New Orleans, LA.

Bowler, W. M. \& Duffy, M. K. (2002). Performance of Encouraged Organizational Citizenship Behavior: Attitudinal Effects on the Self. Annual Proceedings of the Southwest Academy of Management Annual Conference, Saint Louis, MO.

Bowler, W.M., Brass, D.J. In Press. 2006. Relational Correlates of Interpersonal Citizenship Behavior: A Social Network Perspective on Organizational Citizenship Behavior. Journal of Applied Psychology, 91; 70-82.

Burkhardt, M. E. \& Brass, D. J. (1990). Changing patterns or patterns of change: the effects of a change in technology on social network structure and power. Administrative Science Quarterly 35(1): 104(124). 
Burt, R. S. (1992). Getting ahead. Structural holes: the social structure of competition. Cambridge, MA, Harvard University Press.

Cyert, R. M. \& March, J. M. (1963). A Behavioral Theory of the Firm. Englewood Cliffs, CA, Prentice-Hall.

Gouldner, A. W. (1960). The norm of reciprocity: A preliminary statement. American Sociological Review, 25(2): 161-178.

Graham, J.W. (1989). Organizational citizenship behavior: Construct redefinition, operationalization, and validation. Unpublished working paper, Loyola University of Chicago, IL.

Greenwood, R. \& Hinings, C. R. (1996). Understanding radical organizational change: Bringing together the old and the new institutionalism. Academy of Management Review. 21(4): 1022-1054.

Karambayya, R. (1990). Contexts for organizational citizenship behavior: Do high performing and satisfying units have better 'citizens'. York University working paper.

Katz, D. (1964). The motivational basis of organizational behavior. Behavioral Sciences. 9: 131-133.

Koys, D. J. (2001). The Effects of Employee satisfaction, organizational citizenship behavior, and turnover on organizational effectiveness: A unit level, longitudinal study. Personnel Psychology, 54(1): 101-114.

Lamertz, K. (1999). Exchange processes of interpersonal helping in the social structure of work groups. In S.J. Havlovic (Ed.), Proceedings of the 59th Annual Meeting of the Academy of Management. Briarcliff Manor, NY: Academy of Management.

Locke, E. A. \& Latham, G. P. (1990). A Theory of Goal Setting \& Task Performance, Upper Saddle River, NJ, Prentice-Hall Inc.

Moorman, R.H., Blakely, G.L., \& Niehoff, B.P. (1998). Does organizational support mediate the relationship between procedural justice and organizational citizenship behavior? Academy of Management Journal, 41, 351-357.

Moorman, R. H., Blakely, G. L., (1995) Individualism-Collectivism as an individual difference predictor of organizational citizenship behavior. Journal of Organizational Behavior, 16, 127-142.

Morrison, E. W. (1997). Service quality: An organizational citizenship behavior framework. 
Fedor, Donald B. (Ed); Ghosh, Soumen (Ed). (1997). Advances in the management of organizational quality, Vol. 2: An annual series of quality related theory and research papers. (pp. 211 249). Stamford, CT, US: JAI Press, Inc. xi, 288 pp. SEE BOOK.

Organ, D. W. (1988). Organizational citizenship behavior: The good soldier syndrome. Lexington, MA. Lexington Books.

Pearce II, J. A. (1995). A structural analysis of dominant coalitions in small banks. Journal of Management. 21(6): 1075-1096.

Perrow, C. (1993). Complex organizations: A critical essay. New York, McGraw Hill.

Pfeffer, J. \& Salancik, G. R. (1978). The External Control of Organizations. New York, NY, Harper \& Row.

Podsakoff, P. M., MacKenzie, S. B., Paine, J. B., Bacharach, D. G. (2000). Organizational Citizenship Behaviors: A Critical Review of the Theoretical and Empirical literature and suggestions for future research. Journal of Management 26(3): 513-563.

Podsakoff, P. M. \& MacKenzie, S. B. (1997). Impact of organizational citizenship behavior on organizational performance: A review and suggestions for future research. Human Performance, 10(2): 133-151.

Podsakoff, P. M., MacKenzie, S. B. (1994). Organizational Citizenship Behaviors and sales unit effectiveness. Journal of Marketing Research, 31(3), 351-363.

Podsakoff, P. M., MacKenzie, S. B., \& Bommer, W. H. (1996). Transformational leader behaviors and substitutes for leadership as determinants of employee satisfaction, commitment, trust, and organizational citizenship behaviors. Journal of Management, 22, 259-298.

Provan, K. G. \& Skinner, S. J. (1989). Interorganizational dependence and control as predictors of opportunism in dealer-supplier relations. Academy of Management Journal, 32(1): 202-212.

Rioux, S.M, \& Penner, L.A. (2001). The causes of organizational citizenship behavior: A motivational analysis. Journal of Applied Psychology, 86(6): 13061314.

Ruddy, A. S. (Producer), \& Coppola, F. F. (Director). (1972). The Godfather. [DVD]. Hollywood, CA: Paramount Pictures.

Selznick, P. (1949). Foundations of the Theory of Organization. American Sociological Review, 13: 25-35. 
Settoon, R. P., Mossholder, K. W. (2002). Relationship quality and relationship context as antecedents of person- and task-focused interpersonal citizenship behavior. Journal of Applied Psychology, 87(2): 255-267.

Vey, M. A., Campbell, J. P. (2004). In-Role or Extra-Role Organizational Citizenship Behavior: Which Are We Measuring? Human Performance, 17(1): 119-135.

Walz, S. M. (1996). Organizational citizenship behaviors and their effect on organizational effectiveness in limited-menu restaurants. Academy of Management Best Papers Proceedings. 